\title{
Selenium as a potential protective factor against mercury developmental neurotoxicity
}

\section{Citation}

Choi, Anna L., Esben Budtz-Jørgensen, Poul J. Jørgensen, Ulrike Steuerwald, Frodi Debes, Pál Weihe, and Philippe Grandjean. 2008. "Selenium as a Potential Protective Factor Against Mercury Developmental Neurotoxicity." Environmental Research 107 (1) (May): 45-52. doi:10.1016/j.envres.2007.07.006.

\section{Published Version}

doi:10.1016/j.envres.2007.07.006

\section{Permanent link}

http://nrs.harvard.edu/urn-3:HUL.InstRepos:34786597

\section{Terms of Use}

This article was downloaded from Harvard University's DASH repository, and is made available under the terms and conditions applicable to Other Posted Material, as set forth at http:// nrs.harvard.edu/urn-3:HUL.InstRepos:dash.current.terms-of-use\#LAA

\section{Share Your Story}

The Harvard community has made this article openly available.

Please share how this access benefits you. Submit a story.

\section{Accessibility}




\title{
Selenium as a potential protective factor against mercury developmental neurotoxicity
}

\author{
Anna L. Choia, ${ }^{*}$, Esben Budtz-Jørgensen ${ }^{b}$, Poul J. Jørgensen ${ }^{c}$, Ulrike Steuerwald ${ }^{d}$, Frodi \\ Debes $^{\mathrm{d}}, \mathrm{e}$, Pál Weihe ${ }^{\mathrm{d}, \mathrm{e}}$, and Philippe Grandjean ${ }^{\mathrm{a}, \mathrm{e}}$ \\ a Department of Environmental Health, Harvard School of Public Health, Boston, MA, USA \\ b Department of Biostatistics, Institute of Public Health, University of Copenhagen, Copenhagen, Denmark \\ c Institute of Clinical Research, Odense University Hospital, Odense, Denmark \\ d Department of Occupational and Public Health, Faroese Hospital System, Faroe Islands, Denmark \\ e Department of Environmental Medicine, University of Southern Denmark, Odense, Denmark
}

\section{Abstract}

Experimental studies suggest that selenium (Se) may decrease methylmercury $(\mathrm{MeHg})$ toxicity under certain exposure regimens. In epidemiological studies, the exposure to $\mathrm{MeHg}$ occurs from fish and seafood, which are also a source of beneficial nutrients such as selenium. However, little is known about the potential protective effects of dietary Se against MeHg neurotoxicity in humans. The possible interaction was assessed in two birth cohorts in the Faroe Islands, consisting of singleton term births from 1986 to $1987(N=1,022)$, and 1994 to $1995(N=182)$, respectively. Dietary habits in this fishing population included frequent consumption of seafood, including whale meat high in mercury. Both $\mathrm{Hg}$ and Se were measured in cord whole blood. Neurodevelopmental outcomes were evaluated at age 7 years in both cohorts, and the smaller cohort also included neurological assessment on several prior occasions. Each outcome was modeled as a function of $\mathrm{Hg}$ and Se interactions (with adjustments for potential risk factors) by expressing the effects of $\log _{10}(\mathrm{Hg})$ within the lowest $25 \%$, the middle $50 \%$, and the highest $25 \%$ of the Se distribution. Surplus Se was present in cord blood, the average being a 10 -fold molar excess above MeHg. Regression analyses failed to show consistent effects of Se, or statistically significant interaction terms between Se and MeHg. Overall, no evidence was found that Se was an important protective factor against $\mathrm{MeHg}$ neurotoxicity. Prevention, therefore, needs to address MeHg exposures rather than Se intakes. Because of the benefits associated with fish intake during pregnancy, consumers should be advised to maintain a high fish and seafood intake that is low in $\mathrm{Hg}$ contamination. Additional research is needed to determine the identity of the nutrients responsible for the beneficial effects.

\section{Keywords}

Methylmercury; Neuropsychological tests; Prenatal exposure delayed effects; Preschool children; Selenium

\section{Introduction}

Methylmercury $(\mathrm{MeHg})$ is a worldwide contaminant found in seafood and freshwater fish. It is a well-established neurotoxicant that can have serious adverse effects on the developing 
nervous system. The toxicity of $\mathrm{MeHg}$ was known from occupational exposures over 100 years ago. In Minamata, Japan, infants were born with serious neurological damage, even if their exposed mothers were virtually unaffected (Harada, 1995; Igata, 1993). Recent epidemiological studies have found more subtle adverse effects on brain functions at lower levels of MeHg. Mercury-related neuropsychological dysfunctions were most pronounced in the domains of language, attention, and memory, and to a lesser extent, in visuospatial and motor functions. In addition, delayed peak latencies in the brainstem auditory evoked potentials (BAEP) were associated with prenatal and recent $\mathrm{MeHg}$ exposure (Debes et al., 2006; Grandjean et al., 1997; Murata et al., 2004). Impaired performance on behavioral tasks, such as the differential reinforcement of low rates task (DRL), has been found among children prenatally exposed to low-level $\mathrm{MeHg}$ and other environmental contaminants (Stewart et al., 2006). A recent case-control study found that an increased blood-Hg concentration was associated with attention-deficit hyperactivity disorder (ADHD) (Cheuk and Wong, 2006).

Selenium (Se) is a trace mineral that is essential to health. Good sources of Se include fish and seafood, as well as eggs, meat, and vegetables. Se is a constituent of selenoproteins, which are important antioxidant enzymes and catalyst for the production of active thyroid hormone (Rayman, 2000). Although the physiologic functions of Se in the brain are not well understood, studies have found that $\mathrm{Se}$ and certain selenoproteins are particularly well maintained despite prolonged Se deficiency, suggesting the important role of Se in this organ (Chen and Berry, 2003; Whanger, 2001).

Experimental studies have suggested that Se may decrease $\mathrm{MeHg}$ toxicity under certain exposure regimens. In one of the earliest experiments, Parizek and Ostadalova (1967) showed that $\mathrm{Se}$ reduced the acute toxicity of $\mathrm{Hg}$ injected into rats, suggesting that Se might complex with $\mathrm{Hg}$ in the blood to decrease the availability of each element (Ganther et al., 1972). In another model, quails given $\mathrm{MeHg}$ in diet containing tuna survived longer than quails given the same concentration of $\mathrm{MeHg}$ in a corn-soya diet, implying Se that was present in the tuna was responsible for this effect (Ganther et al., 1972). In a separate study in rats, Ganther et al. (1972) showed that MeHg toxicity was decreased by the levels of Se in a diet that were comparable to that was supplied by tuna. In an in utero $\mathrm{MeHg}$ and Se study on mice, the group that was given the lowest amount of Se and the highest dose of $\mathrm{MeHg}$ was mostly adversely affected in neurobehavioral outcome (Watanabe et al., 1999). A recent study on rodents showed that antioxidant nutrients $\mathrm{Se}$ and Vitamin $\mathrm{E}$ in a diet may alter $\mathrm{MeHg}$ reproductive and developmental toxicity (Beyrouty and Chan, 2006).

In epidemiological studies, the exposure to methylmercury occurs from fish and seafood, which are also a source of beneficial nutrients such as selenium. However, little is known about the potential protective effect of Se against $\mathrm{MeHg}$ neurotoxicity in humans. The current study was undertaken to assess the potential interaction between these two elements in the Faroe Islands, a Nordic fishing community with limited social differences, where meals included frequent consumption of seafood and pilot whale meat (Grandjean et al., 1992). The traditional intake of whale meat is a source of excess exposure to $\mathrm{MeHg}$, while other types of seafood contain lower MeHg concentrations (Weihe et al., 2005). We modeled neurobehavioral examinations conducted on two cohorts in this community incorporating Se and MeHg exposures and potential confounders to evaluate whether increased Se levels were associated with decreased mercury-related neuropsychological dysfunctions.

\section{Materials and methods}

\subsection{Study population}

Two cohorts of singleton births were assembled in the Faroe Islands, where the marine diet includes also the consumption of pilot whale meat, a source of MeHg exposure. Cohort 1 was 
assembled during a 21-month period of 1986-1987 (Grandjean et al., 1992, 1997). Of the 1022 children, a total of 917 completed the neuropsychological examinations at age 7 years. Cohort 2 consisted of 182 infants recruited from births at the National Hospital in Torshavn, Faroe Islands (Steuerwald et al., 2000). Children who were born before the 36th week in gestation, or had congenital neurologic disease were excluded. The Faroese Ethical Review Committee approved the protocols of both studies, and written informed consent was obtained from all parents.

\subsection{Measurements of exposure}

We used the mercury concentration in whole blood from the umbilical cord as the primary indicator of prenatal exposure to MeHg (Grandjean et al., 1992, 1997). Cord blood samples were obtained at birth and mercury analysis was performed in duplicate by flow-injection coldvapor atomic absorption spectrometry after digestion of the sample in a microwave oven. Details of analytic methods and quality control procedures are described elsewhere (Grandjean et al., 1992). Mercury concentrations reported in units of micrograms/liter $(\mu \mathrm{g} / \mathrm{L})$ may be converted to nanomoles/liter ( $\mathrm{nmol} / \mathrm{L}$ ) by multiplying by 5.0 .

Se in cord blood samples were determined by electrothermal atomic absorption with Zeeman background correction. Methods and procedure of the analysis have been documented (Grandjean et al., 1992). Results of Se concentration in micrograms/liter $(\mu \mathrm{g} / \mathrm{L})$ may be converted to micromoles/liter $(\mu \mathrm{mol} / \mathrm{L})$ by dividing by 79 .

\subsection{Outcome measurements}

Neuropsychological tests were chosen to include tasks that would be affected by the neuropathological abnormalities that have been described in congenital $\mathrm{MeHg}$ poisoning (Harada, 1995; National Research Council, 2000). The tests reflect different domains of brain function.

Details of test administration and results for the two cohorts at 7 years of age have been previously published (Grandjean et al., 1997). We included tests of motor function Neurobehavioral Evaluation System (NES) (Dahl et al., 1996; Letz and Baker, 1998) - Finger Tapping Test and Hand-Eye Coordination Test; attention - NES Continuous Performance Test and Wechsler Intelligence Scale for Children-Revised (WISC-R) (Wechsler, 1974); visuospatial performance - WISC-R Block Design and Bender Visual Motor Gestalt Test, copy condition (Schlange et al., 1977) (a copying block design test was used in cohort 2 in place of the Bender Test); language - Boston Naming Test (Kaplan et al., 1983); and shortterm memory - California Verbal Learning Test (Children) (Delis et al., 1994).

Neurologic examination (Prechtl, 1977) of the cohort 2 children was carried out at 2 weeks (adjusted for gestational age), 18 months, 42 months, and 90 months. To assess functional abilities, reflexes and responses, and the stability of behavioral status during the examination, items are classified as clinically optimal, questionable, or suboptimal. The neurologic optimality score (NOS) is the number of items (out of 60) that are rated optimal. Details of the examination and results at 2 weeks have been published (Steuerwald et al., 2000).

\subsection{Measurements of confounders}

The set of confounders for cohort 1 has been reported in Grandjean et al. (1997). The covariates were chosen based on the prior knowledge of potential influence on the outcome variables and the epidemiologic setting in the Faroe Islands (Budtz-Jorgensen et al., 2007a). The child's characteristics included sex, age, and medical risk factor at birth and whether the child was in daycare were determined as binary (yes/no) variables. Characteristics of the parents considered 
were maternal Raven intelligence score and professional training, paternal professional training and employment.

A similar set of confounders was used for cohort 2, including the Home Observation for Measurement of the Environment (HOME) evaluation (Caldwell and Bradley, 1985). Since the cohort 2 children were already in school at age 90 months, daycare was not included as a confounder. Previously defined medical risk factors (Grandjean et al., 1997) (97\% did not have any) did not show any relationship with mercury exposure and were not further considered. Covariates included in the NOS analyses were the same for the 2 weeks (Steuerwald et al., 2000), although without age correction for gestational age.

\subsection{Statistical analyses}

Most of the neurobehavioral test scores approximated a Gaussian distribution except for Block Design (transformed to the square root of the score +1 ), and the number of missed responses on the Continuous Performance Test (transformed to the natural logarithm of the score +1 ). The cord blood mercury and Se levels were $\log$ (base 10) transformed. We performed multiple regression analyses for each of the neuropsychological outcomes, with the mercury and selenium levels, and an interaction parameter between the two exposures, and potential confounders as independent variables. The Se levels were expressed in three groups according to the quartiles of the distribution - lowest $25 \%$, middle $50 \%$, and highest $25 \%$, respectively. The Se levels in cohort 2 were lower than those of cohort 1 . Cutoff points for quartiles of Se levels were, therefore, different for the two cohorts. We assessed the significance of the interaction of mercury with the three groups of Se exposure and possible trends of mercury exposure among the three Se groups. The three groups of Se in cohort 1 were: $<100 \mu \mathrm{g} / \mathrm{L}, 100$ $120 \mu \mathrm{g} / \mathrm{L}$, and $>120 \mu \mathrm{g} / \mathrm{L}$; and in cohort $2:<93,93-112$, and $>112 \mu \mathrm{g} / \mathrm{L}$. Because the test scores were not of the same magnitude and transformation had been used, regression coefficients were expressed as change (in percent of the standard deviation of the unadjusted outcome parameter) in neurobehavioral performance associated with a doubling of the cord blood mercury by Se exposure levels. We report two-sided $p$-values.

\section{Results}

The geometric mean cord blood $\mathrm{Hg}$ and Se levels were similar in cohorts 1 and 2 (Table 1), although cohort 2 had lower cord blood $\mathrm{Hg}$ and Se levels. The interquartile range (IQR) of $\mathrm{Hg}$ concentrations spanned almost a factor of three, whereas the IQR of Se levels had narrow ranges. Surplus Se was present in cord blood, the average being a 10-fold molar excess above $\mathrm{MeHg}$. The correlation between $\mathrm{Hg}$ and Se was 0.35 ( $p<0.001$ ) for cohort 1 (Fig. 1), and 0.29 $(p<0.001)$ for cohort 2 . The geometric means and IQR of $\mathrm{Hg}$ exposure among quartiles of $\mathrm{Se}$ levels were similar in both cohorts (Table 2), with levels of $\mathrm{Hg}$ in cohort 1 slightly higher than those of cohort 2 in all Se groups. $\mathrm{Hg} / \mathrm{Se}$ molar ratio had a strong correlation with $\mathrm{Hg}(r=0.98$, $p<0.001 ; r=0.97, p<0.001$ for cohorts 1 and 2, respectively), but the $\mathrm{Se} / \mathrm{Hg}$ molar ratio with Se was weak ( $r=-0.18, p<0.001$ for cohort $1 ; r=-0.12, p=0.14$ for cohort 2$)$. The $\mathrm{Hg} / \mathrm{Se}$ molar ratio did not remain constant, but rather, it increased linearly as $\mathrm{Hg}$ concentration increased (Fig. 2).

Maternal, child, and household characteristics for both cohorts are described elsewhere (Grandjean et al., 1997, 1992). Briefly, similar numbers of boys and girls participated in both cohorts. Fourteen infants in cohort 1 had birth weights below $2500 \mathrm{~g}$, but none in cohort 2. In cohorts 1 and 2, 49\% and 51\% of mothers consumed three or more fish meals per week, and $51 \%$ and $35 \%$ consumed more than two whale meat meals per month, respectively, confirming that this fishing population is highly dependent on seafood, including pilot whale. Most of the pregnant women were non-smokers (61\% in cohort 1, and 69\% in cohort 2). Similarly, only $24 \%$ occasionally drank alcoholic beverages in cohort 1 , and $13 \%$ in cohort 2 . 
We constructed multivariate models to assess the association between change in neurobehavioral outcomes with mercury among the three groups of selenium levels with adjustment for potential confounders for cohorts 1 and 2 (Tables 3 and 4). Although interactions between $\mathrm{MeHg}$ and Se were significant on the finger tapping non-preferred hand condition, total missed response on reaction time, and similarities on the WISC-R, no clear overall trends were observed. The mercury effect was the strongest with the non-preferred hand finger tapping and the CPT missed response in the low selenium group, but it was strongest with similarities in the high Se group. The only significant interaction was on the Boston Naming Test with clues in cohort 2, with the strongest mercury effect in the medium Se group. Except for a near significance between $\mathrm{Se}$ and $\mathrm{MeHg}$ with NOS at 2 weeks, no significant interactions were found with the cohort 2 neurologic examinations (Table 5). Overall, there was no consistent trend in effects of mercury on outcomes in the three Se groups in both cohorts.

\section{Discussion}

We found no evidence that Se was a significant protective factor against $\mathrm{MeHg}$ neurotoxicity in the Faroese study population-increased Se levels were not associated with decreased mercury-related neuropsychological dysfunctions.

In contrast, numerous animal studies have reported that Se may decrease $\mathrm{MeHg}$ toxicity (Beyrouty and Chan, 2006; Ganther et al., 1972; Parizek and Ostadalova, 1967; Whanger, 1992). These experimental studies provide an understanding in how Se and MeHg may interact under different exposure regimens. Groups of mice, for example, were given low dietary amounts of Se in a study to investigate the effects of $\mathrm{MeHg}$ exposure and in utero Se deficiency on neurobehavior outcome (Watanabe et al., 1999). In a study to examine the concentration of blood and brain MeHg and Se that model the conditions of human exposure more closely, the female rats were exposed to three levels of $\mathrm{MeHg}$ and two levels of dietary amounts of Se, with one level at the low end of recommended intakes from laboratory studies (Newland et al., 2006).

Under some circumstances, episodic exposures can result in bolus doses of $\mathrm{MeHg}$ during sensitive windows of development. Preliminary results from a recent experimental study found no difference in $\mathrm{Hg}$ accumulation in the brain and neuronal damage between bolus versus constant MeHg doses (Sakamoto et al., 2007). Since most animal models are deficient in Se, it is therefore unlikely that bolus doses of $\mathrm{MeHg}$ could temporarily overwhelm available Se.

Any protective effect of Se against mercury-related neuropsychological dysfunctions in humans, however, has not been documented so far. Se, a trace mineral, is an essential nutrient of fundamental importance to human health. Deficiency in Se in humans has been linked to viral infections, hypothroidism, cardiovascular diseases, and adverse mood states (Rayman, 2000). The latter was postulated to be caused by low levels of Se, which influences compounds with hormonal activity and neurotransmitters in the brain (Whanger, 2001). Adequate dietary intake of Se is, therefore, crucial for good health.

We assessed the possible interaction between these two elements with a cohort of over 1000 births and a secondary cohort of over 180 births in a community with high MeHg exposure from consumption of pilot whale meat and Se from fish and seafood. The large study population provided statistical power to detect of interactions of clinical relevance. Comparing only the low and high Se exposure groups for all outcomes in Table 3, the length of the confidence intervals is approximately $20 \%$ (the nice agreement is a result of expressing the standardized effects of the test scores which were not of the same magnitude and that transformation was used for some of the scores). This means that in this study, a difference in mercury effects of $20 \%$ would have been significant. The $20 \%$ difference that we fail to see refers to each of the 
single outcome analyses performed, indicating the strength of power in our study. Because we actually compared three Se groups, the real power would be somewhat stronger.

Se in cord blood, which was used as a biomarker of Se for the study, reflects long-term exposure (WHO, 1987). Plasma or serum Se reflects only short-term status (Thomson, 2004). The cord blood Se concentrations in our cohorts were higher than those seen in populations that were not dependent on marine food (Grandjean et al., 1992).

Previous established results from cohort 1 show that decrements in specific functional domains of attention, language, and verbal memory were associated with prenatal $\mathrm{MeHg}$ exposure (Grandjean et al., 1997). The present results show no clear trend of adverse mercury effects on the neurodevelopmental outcomes with varying levels of selenium. In support of a possible selenium interaction, adverse mercury-related effects were found with finger tapping with preferred hand, and this effect was significant only in low Se subgroup, but not in the medium or high Se groups, thereby resulting in a non-significant interaction. Similarly, significant $\mathrm{Hg}$ related dysfunctions were only with low and medium Se groups on the continuous performance test average reaction time, but not on the high Se group. Except for the borderline statistical significant interactions of three outcomes - total missed response of continuous performance test, non-preferred hand condition of finger tapping, and similarities in the WISC-R, most of the interactions in cohort 1 were weak. Although the three interactions were significant, the patterns of adverse mercury effects were inconsistent. The observed interactions may be a chance finding from the 17 outcomes, or consequent to residual confounding. Despite the small sample size of cohort 2, a similar inconsistent trend was found with Boston Naming Test with cues, the only outcome with a significant interaction.

Molar ratio has been used to examine the potential interactions between $\mathrm{Hg}$ and $\mathrm{Se}$ (Newland et al., 2006). Among our subjects, surplus Se was present in cord blood, the average being a 10-fold molar excess above $\mathrm{MeHg}$ (Table 1). Compared to the experimental studies, animals with $\mathrm{Hg} / \mathrm{Se}$ molar ratio close to 1:1 did not show any overt signs of $\mathrm{Hg}$ or Se intoxication despite high levels of $\mathrm{Hg}$ and $\mathrm{Se}$, suggesting the mutually protective effect against the toxicity caused by the elements (Cuvin-Aralar and Furness, 1991). A recent experimental study found that appearance of overt neurological symptoms resulted from a molar excess of $\mathrm{Hg}$ over $\mathrm{Se}$, while a molar excess of Se prevents such manifestations (Reed et al., 2006). The level of Se concentrations in cord blood and the excess molar concentration of Se suggested that all Faroese children are Se sufficient. Our results showing the lack of interaction between the two elements are in agreement with the Reed et al. findings at high Se intake levels.

The considerable scattering between $\mathrm{Hg}$ and Se (Fig. 1) suggests that variable amounts of Se are not bound to $\mathrm{Hg}$ in cord blood. Unlike $\mathrm{Hg}$ concentration, the Se concentration generally varied within a narrower interval (Table 1, Fig. 1). As $\mathrm{Hg}$ concentration increased, the $\mathrm{Hg} / \mathrm{Se}$ molar ratio did not remain constant, but rather, it increased linearly (Fig. 2).

In epidemiological studies, fish intake may seem to compensate for some $\mathrm{MeHg}$-associated effects. MeHg is a common contaminant of seafood, which also contains major essential nutrients. Recent published results on cohort 1 found that adjustment of fish intake and the corresponding error resulted in more adverse MeHg-related neuropsychological dysfunctions (Budtz-Jørgensen et al., 2007b). Similar results were found in cohort 2 (results not shown). These findings suggest that to prevent underestimation, the estimations of toxic effects of mercury and the beneficial effects of seafood should be mutually adjusted. Similar to the approach for fish intake, our adjustment for Se in the statistical models did not reveal a greater adverse effect of $\mathrm{MeHg}$ on the outcomes, thus suggesting that Se intake cannot explain the significant benefits associated with fish intake. Correlations between fish intake and Se were low in both cohorts $(r=0.094, p=0.005$ and $r=0.24, p=0.004$ for cohorts 1 and 2, 
respectively), suggesting that although fish is a source of Se, there are other dietary Se sources such as plants and meats.

There are several limitations in the interpretation of our findings. First, the narrower range of $\mathrm{Hg}$ exposure within each Se group might limit a possible interaction between the two elements. However, we found similar results when we included continuous Se levels (instead of the three Se categories) in the interaction models. In addition, although our study population is a rather homogenous community with limited social differences, additional confounders that were not adjusted for in the analyses may result in residual confounding. We had limited power to assess the interaction in cohort 2, which might likely explain the null findings. However, the lack of significant tendencies of adverse mercury-related effects among Se groups was consistent with those found in cohort 1 .

In conclusion, $\mathrm{Se}$ was not found to have significant protective effect against $\mathrm{MeHg}$ neurotoxicity. The Se concentrations suggested that all the study children were fully $\mathrm{Se}$ sufficient. In addition, the Se intake cannot explain the significant benefits associated with fish intake. Prevention, therefore, needs to address MeHg exposures rather than Se intakes. Because of the benefits associated with fish intake during pregnancy, consumers should be advised to maintain a high fish seafood intake that is low in $\mathrm{Hg}$ concentration. Additional research is needed to determine the identity of the nutrients responsible for the beneficial effects.

\section{Acknowledgements}

This study was supported by the U.S. National Institute of Environmental Health Sciences (ES09797 and ES11687) and the European Commission (ANEMONE, QLK4-CT-2001-00186). The contents of this paper are solely the responsibility of the authors and do not represent the official views of the NIEHS, NIH or any other funding agency.

\section{References}

Beyrouty P, Chan HM. Co-consumption of selenium and vitamin E altered the reproductive and developmental toxicity of methylmercury in rats. Neurotoxicol Teratol 2006;28:49-58. [PubMed: 16427250]

Budtz-Jørgensen E, Keiding N, Grandjean P, Weihe P. Confounder selection in environmental epidemiology: Assessment of health effects of prenatal mercury exposure. Ann Epidemiol 2007a; $17: 27-35$.

Budtz-Jørgensen E, Weihe P, Grandjean P. Underestimation of adverse effects of mercury exposure unadjusted for beneficial effects of seafood consumption. Environ Health Perspect 2007b;115:323327.

Caldwell, BM.; Bradley, RH. Home Observation for Measurment of the Environment. New York: Dorsey; 1985.

Chen J, Berry MJ. Selenium and selenoproteins in the brain and brain diseases. J Neurochem 2003;86:112. [PubMed: 12807419]

Cheuk DK, Wong V. Attention-deficit hyperactivity disorder and blood mercury level: a case-control study in Chinese children. Neuropediatrics 2006;37:234-240. [PubMed: 17177150]

Cuvin-Aralar MLA, Furness RW. Mercury and Selenium Interaction: a review. Ecotoxicol Environ Saf 1991;21:348-364. [PubMed: 1868791]

Dahl R, White RF, Weihe P, Sørensen N, Letz R, Hudnell HK, Otto DA, Grandjean P. Feasibility and validity of three computer-assisted neurobehavioral tests in 7-year-old children. Neurotoxicol Teratol 1996;18:413-419. [PubMed: 8866532]

Debes F, Budtz-Jørgensen E, Weihe P, White RF, Grandjean P. Impact of prenatal methylmercury exposure on neurobehavioral function at age 14 years. Neurotoxicol Teratol 2006;28:363-375. [PubMed: 16647838]

Delis, DC.; Kramer, JH.; Kaplan, E.; Ober, BA. California Verbal Learning Test (Children). Psychological Corp; San Antonio, TX: 1994. 
Ganther HE, Goudie C, Kopecky MJ, Wagner POSH, Hoekstra WG. Selenium:relation to decreased toxicity of methylmercury added to diets containing tuna. Science 1972:1122-1124. [PubMed: 5062150]

Grandjean P, Weihe P, Jørgensen PJ, Clarkson T, Cernichiari E, Viderø T. Impact of maternal seafood diet on fetal exposure to mercury, selenium, and lead. Arch Envrion Health 1992;47:185-195.

Grandjean P, Weihe P, White RF, Debes F, Araki S, Yokoyama K, Murata K, Sørensen N, Dahl R, Jørgensen PJ. cognitive deficit in 7-year-old children with prenatal exposure to methylmercury. Neurotoxicol Teratol 1997;19:417-428. [PubMed: 9392777]

Harada M. Minamata disease: methylmercury poisoning in japan caused by environmental pollution. Crit Rev Toxicol 1995;25:1-24. [PubMed: 7734058]

Igata A. Epidemiological and clinical features of minamata disease. Environ Res 1993;63:157-169. [PubMed: 8404770]

Kaplan, E.; Goodglass, H.; Weintraub, S. The Boston Naming Test. Lea and Febiger; Philadelphia: 1983.

Letz, R.; Baker, EL. NES2 Neurobehavioral Evaluation System Manual. Neurobehavioral System; Winchester, MA: 1998.

Murata K, Weihe P, Budtz-Jørgensen E, Jørgensen PJ, Grandjean P. Delayed brainstem auditory evoked potential latencies in 14-year-old children exposed to methylmercury. J Pediatr 2004;144:173-177.

National Research Council. Toxicological Effects of Methylmercury. National Academy Press; Washington, DC: 2000.

Newland MC, Reed MN, LeBlanc A, Donlin WD. Brain and blood mercury and selenium after chronic and developmental exposure to methylmercury. Neurotoxicology 2006;27:710-720. [PubMed: 16824603]

Parizek J, Ostadalova I. The protective effect of small amounts of selenite in sublimate intoxication. Experientia 1967;23:142-143. [PubMed: 6032113]

Prechtl, HFR. The neurological examination of the full-term newborn infant. 2. Clinics in Developmental Medicine; Heinemann, London: 1977.

Rayman MP. The importance of selenium to human health. Lancet 2000;356:233-241. [PubMed: 10963212]

Reed MN, Paletz EM, Newland MC. Gestational exposure to methylmercury and selenium: effects on a spatial discrimination reversal in adulthood. Neurotoxicology 2006;27:721-732. [PubMed: 16759706]

Sakamoto, M.; Shunichi, H.; Kakita, A.; Murata, K.; Satoh, H. Effects of spike exposure of methylmercury on mercury accumulation and neuronal degeneration in the brain. Poster presented at the International Conference on Fetal Programming and Developmental Toxicity; Faroe Islands. 20-24 May 2007; 2007 [Accessed 5/20/07]. Available: 〈http://www.pptox.dk/portals/0/p7.pdf〉

Schlange, H.; Stein, B.; von Beotticher, I.; Taneli, S. Göttinger Formreproduktions-Test. Verlag für Psychologie; Göttingen, Germany: 1977.

Steuerwald U, Weihe P, Jørgensen PJ, Bjerve K, Brock J, Heinzow B, Budtz-Jørgensen E, Grandjean P. Maternal seafood diet, methylmercury exposure, and neonatal neurologic function. Pediatrics 2000;136:599-605.

Stewart PW, Sargent DM, Reihman J, Gump BB, Lonky E, Darvill T, Hicks H, Pagano J. Response inhibition during differential reinforcement of low rates (DRL) schedules may be sensitive to lowlevel polychlorinated biphenyl, methylmercury, and lead exposure in children. Environ Health Perspect 2006;114:1923-1929. [PubMed: 17185286]

Thomson CD. Assessment of requirements for selenium and adequacy of selenium status: a review. European J Clinic Nutr 2004;58:391-402.

Watanabe C, Yin K, Kasanuma Y, Satoh H. In utero exposure to methylmercury and Se deficiency converge on the neurobehavioral outcome in mice. Neurotoxicol Teratol 1999;21:83-88. [PubMed: 10023805]

Wechsler, D. Wechsler Intelligence Scale for Children-Revised. Psychological Corp; New York, NY: 1974.

Weihe P, Grandjean P, Jørgensen PJ. Application of hair-mercury analysis to determine the impact of a seafood advisory. Environ Res 2005;97:200-207. [PubMed: 15533336] 
Whanger PD. Selenium in the treatment of heavy metal poisoning and chemical carcinogens. J Trace Elem Electrolytes Health Dis 1992;6:209-221. [PubMed: 1304229]

Whanger PD. Selenium and the brain: a review. Nutr Neurosci 2001;4(2):81-97. [PubMed: 11842884]

World Health Organization (WHO). Selenium. Geneva, Switzerland: 1987. 


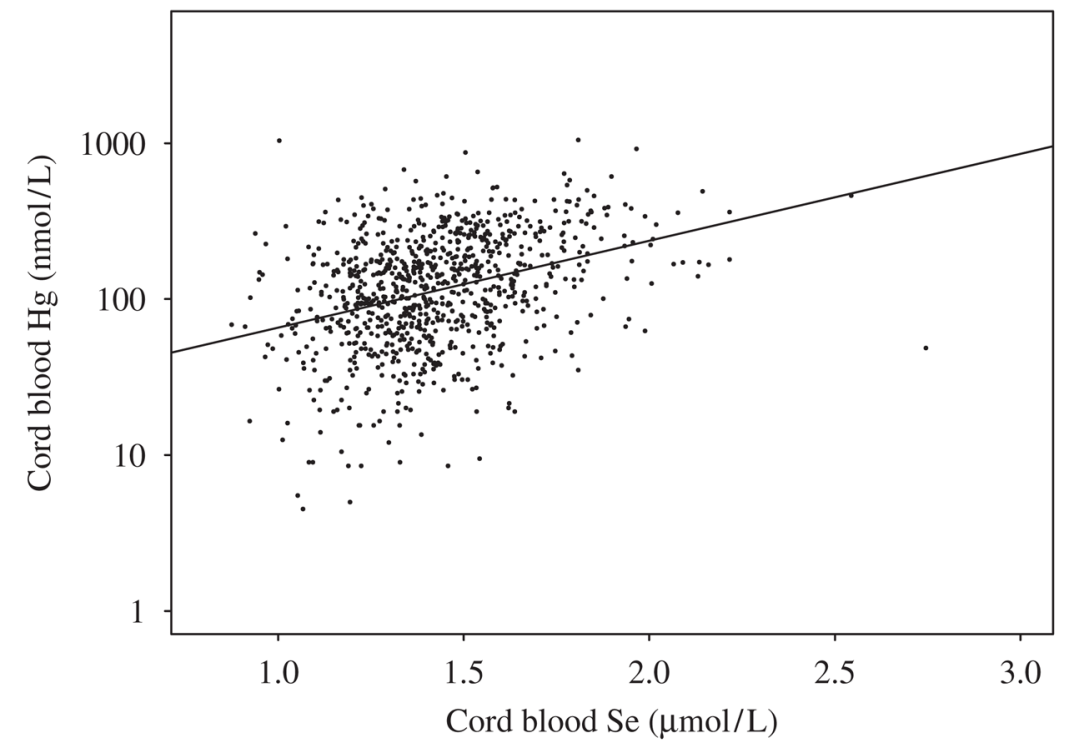

Fig. 1.

Plot of mercury and selenium molar concentrations in cord blood of the first Faroese birth cohort. 


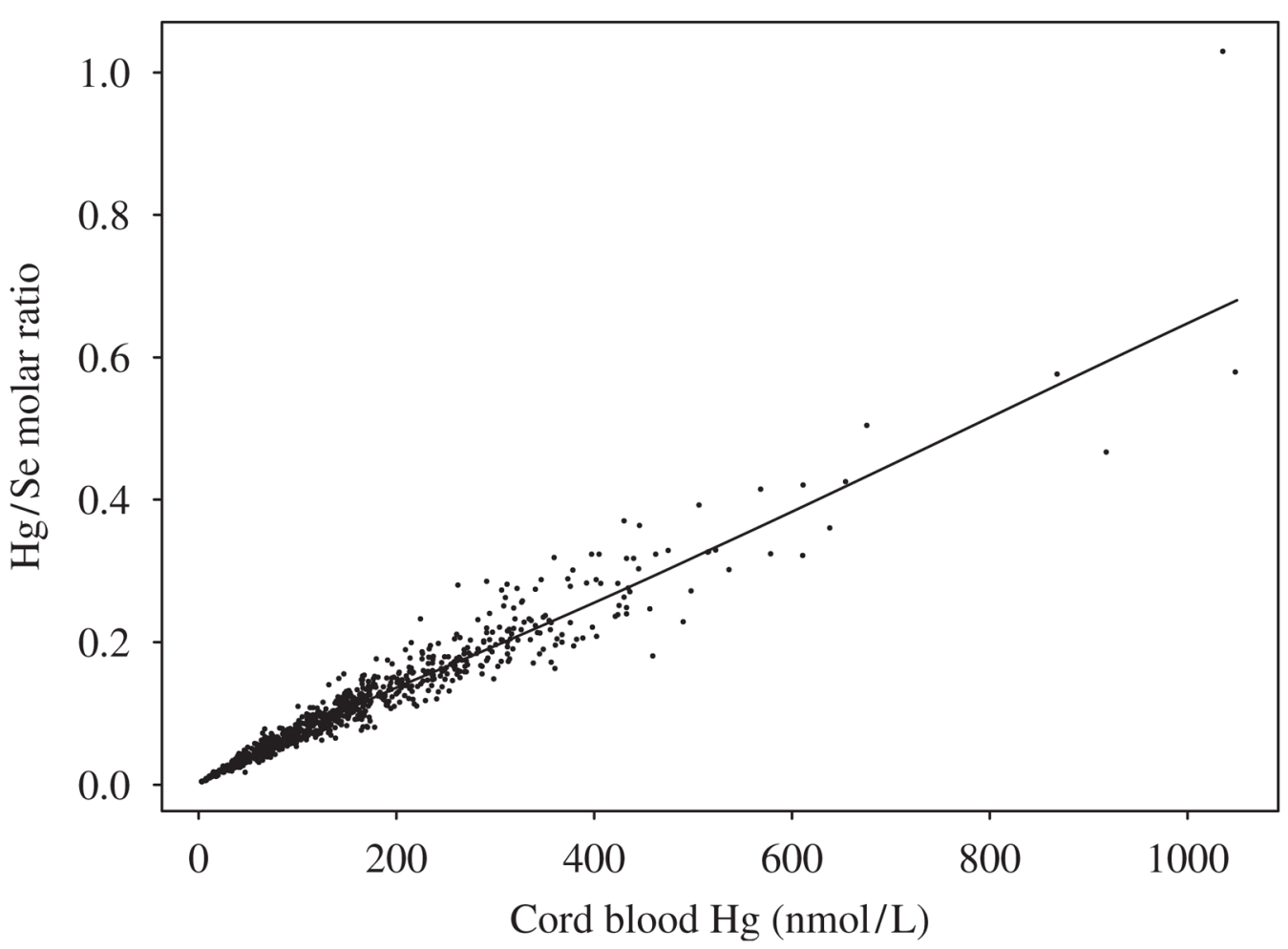

Fig. 2.

Plot of cord blood mercury molar concentration versus $\mathrm{Hg} / \mathrm{Se}$ molar ratio of the first Faroese birth cohort. 


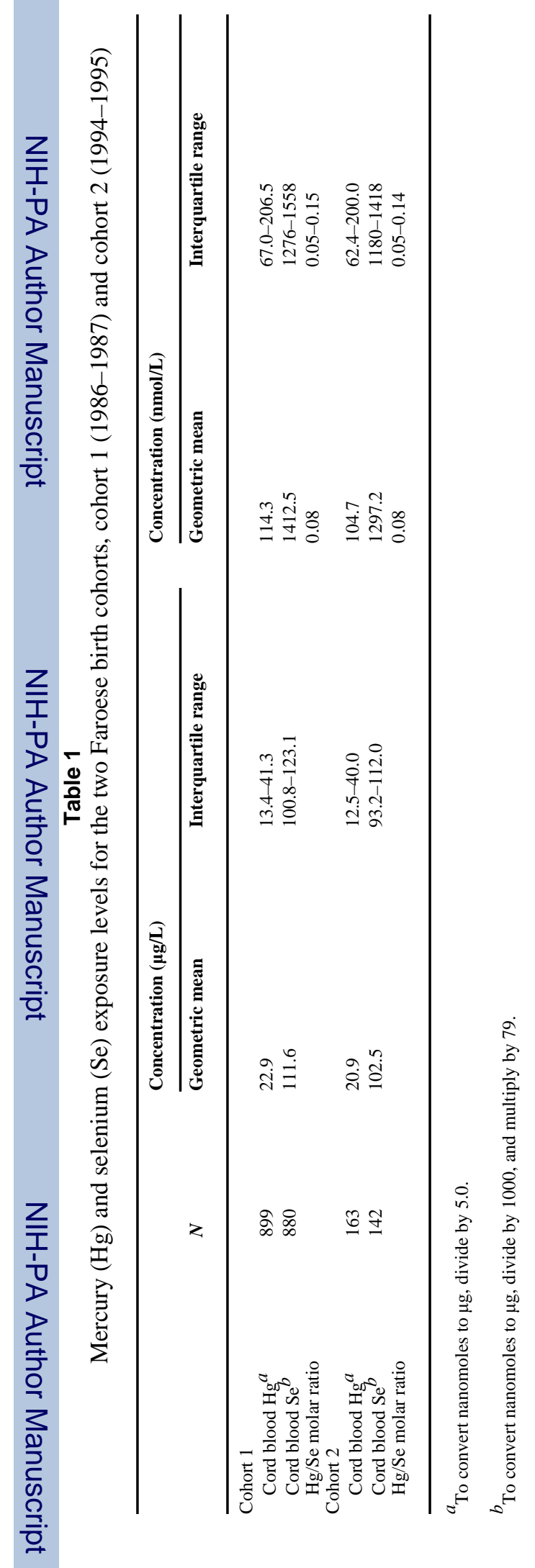


Table 2

Mercury $(\mathrm{Hg})$ exposure by quartiles of selenium $(\mathrm{Se})$ levels for the two Faroese birth cohorts

\begin{tabular}{llll}
\hline & & Hg exposure levels $(\boldsymbol{\mu g} / \mathbf{L})$ & \\
\cline { 4 - 4 } Se groups & $\boldsymbol{N}$ & Geometric mean & Interquartile range \\
\hline Cohort 1 & & & $9.6-29.9$ \\
$\quad$ Quartile 1 $(<100 \mu \mathrm{g} / \mathrm{L})$ & 211 & 16.1 & $13.0-36.6$ \\
$\quad$ Quartiles 2-3 $(100-120 \mu \mathrm{g} / \mathrm{L})$ & 413 & 21.5 & $20.1-56.6$ \\
$\quad$ Quartile 4 $(>120 \mu \mathrm{g} / \mathrm{L})$ & 275 & 32.9 & $9.0-34.1$ \\
Cohort 2 & 35 & 15.8 & $11.5-33.6$ \\
$\quad$ Quartile 1 $(<93 \mu \mathrm{g} / \mathrm{L})$ & 72 & 19.3 & $16.0-49.5$ \\
$\quad$ Quartiles 2-3 $(93-112 \mu \mathrm{g} / \mathrm{L})$ & 35 & 29.8 & \\
Quartile 4 $(>112 \mu \mathrm{g} / \mathrm{L})$ & & & \\
\hline
\end{tabular}




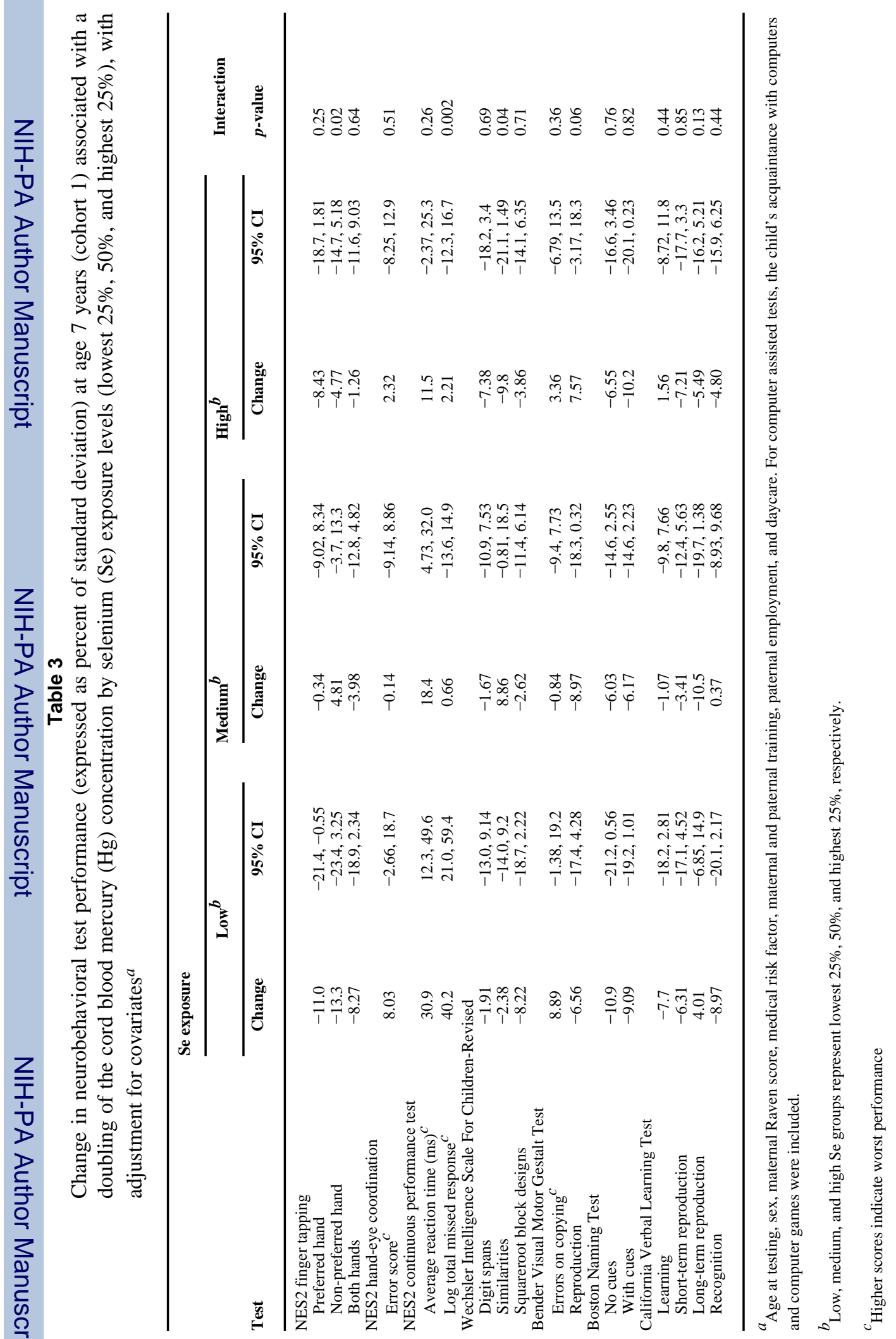




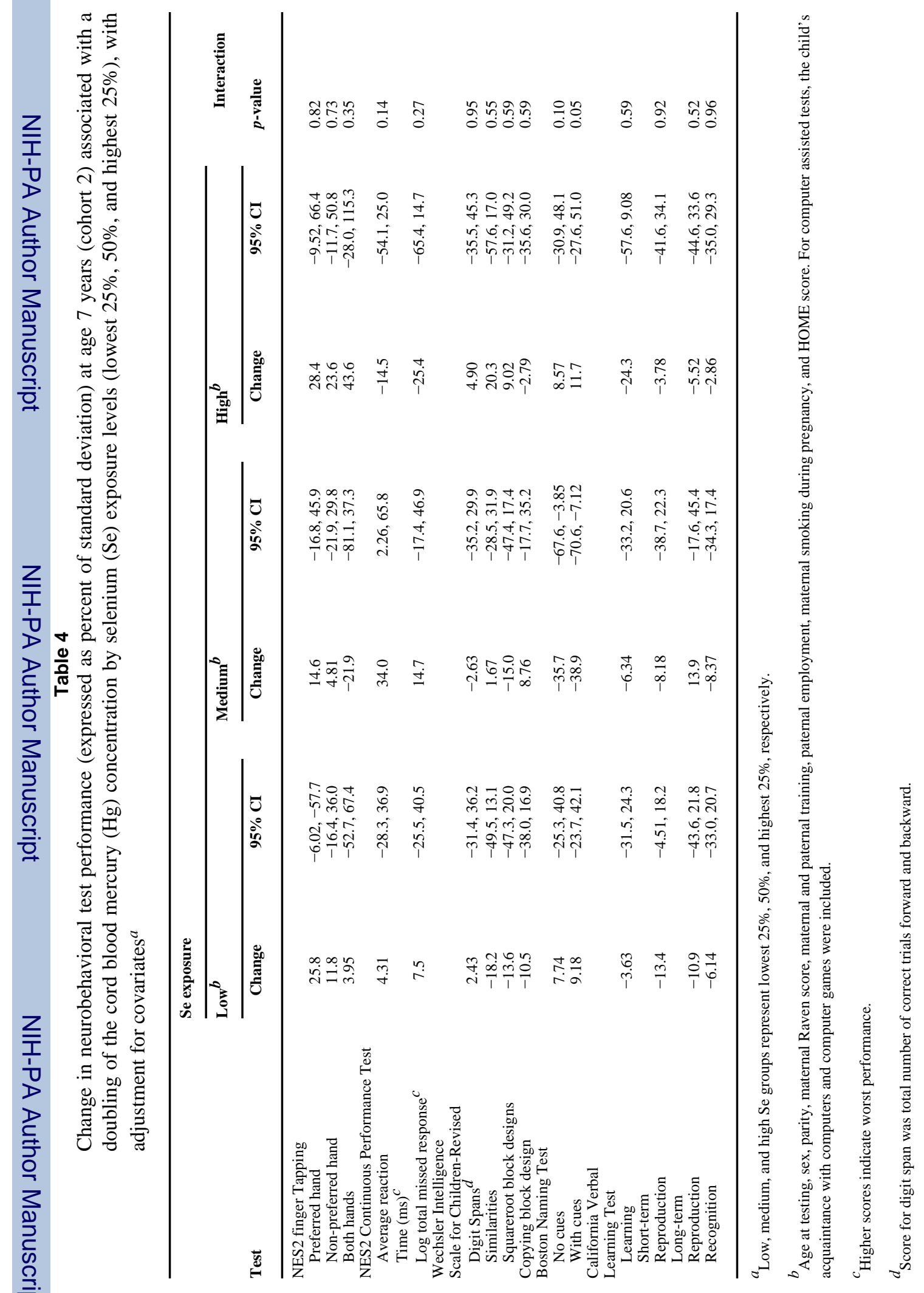


Choi et al.

Page 16

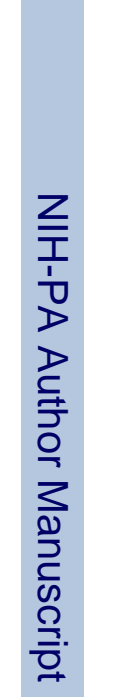

$\vec{\Xi} \overline{0}$

造造

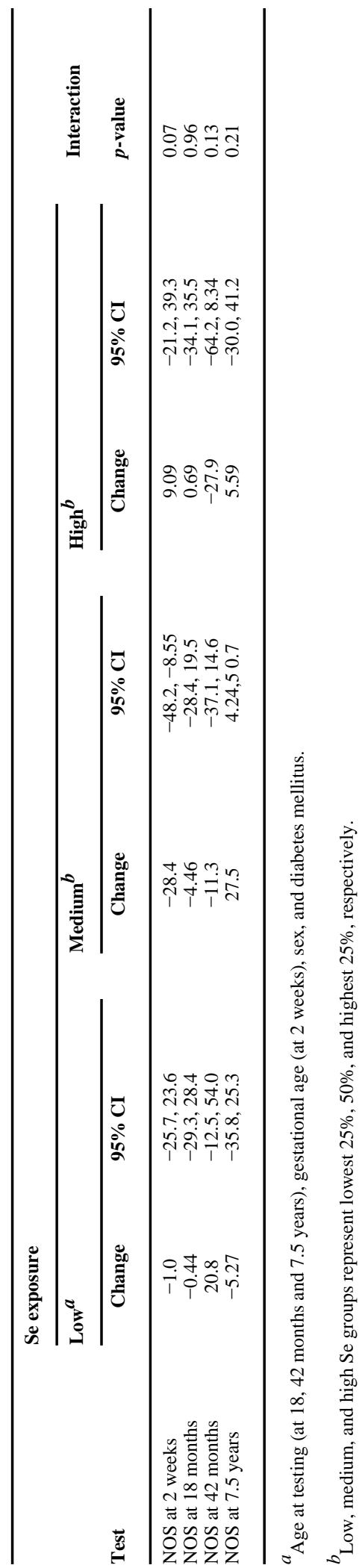

음.

Environ Res. Author manuscript; available in PMC 2009 May 1. 